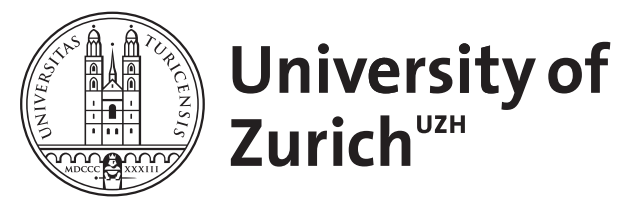

\title{
The Sisyphus syndrome in health revisited
}

Zweifel, Peter ; Steinmann, Lukas ; Eugster, Patrick

\begin{abstract}
Health care may be similar to Sisyphus work: When the task is about to be completed, work has to start all over again. To see the analogy, consider an initial decision to allocate more resources to health. The likely consequence is an increased number of survivors, who will exert additional demand for health care. With more resources allocated to health, the cycle starts over again. The objective of this paper is to improve on earlier research that failed to find evidence of a Sisyphus syndrome in industrialized countries. This time, there are signs of such a cycle, which however seems to have faded away recently.
\end{abstract}

DOI: https://doi.org/10.1007/s10754-005-1864-6

Posted at the Zurich Open Repository and Archive, University of Zurich ZORA URL: https://doi.org/10.5167/uzh-1211

Journal Article

Published Version

Originally published at:

Zweifel, Peter; Steinmann, Lukas; Eugster, Patrick (2005). The Sisyphus syndrome in health revisited. International Journal of Health Care Finance and Economics, 5(2):127-145.

DOI: https://doi.org/10.1007/s10754-005-1864-6 


\title{
The Sisyphus Syndrome in Health Revisited
}

\author{
PETER ZWEIFEL \\ LUKAS STEINMANN \\ PATRICK EUGSTER
}

pzweifel@soi.unizh.ch

Socioeconomic Institute, University of Zurich, Hottingerstrasse 10 CH-8032 Zurich, Switzerland

Health care may be similar to Sisyphus work: When the task is about to be completed, work has to start all over again. To see the analogy, consider an initial decision to allocate more resources to health. The likely consequence is an increased number of survivors, who will exert additional demand for health care. With more resources allocated to health, the cycle starts over again. The objective of this paper is to improve on earlier research that failed to find evidence of a Sisyphus syndrome in industrialized countries. This time, there are signs of such a cycle, which however seems to have faded away recently.

Keywords: production of health, health care expenditure, dynamic feedback, Sisyphus syndrome

JEL classification: I10, J10

\section{Introduction and Motivation}

When the British National Health Service was created, its founders expected the problem of ill health to fade away. After all, once people have access to good medical care, they should live healthy and happy to the end of their lives. History has proven this expectation to be entirely false. Indeed, decision makers in health policy are haunted by a quite different suspicion, which Zweifel and Ferrari (1992) dubbed the Sisyphus syndrome. Health care services could be something like the work of Sisyphus, a Greek hero who was ordered by the Gods to push a big rock uphill. But just before the very top, the rock would slip from his hands so he had to start all over again.

Consider the following sequence of events in health care. Initially, politicians decide to allocate more resources to health. If effective this intervention causes people that would have otherwise died to survive. With more survivors around, there will be additional demand for health care services. To the extent that this is financed out of private resources, there is not too much of a problem. Individuals will adjust their health insurance policies accordingly and allocate a greater share of their income to health care. However, most of these services are covered by public health insurance. Rather than accepting to pay themselves, especially older voters have an incentive to get politicians to reallocate the public budget in favor of health. The increase in health care expenditure $(H C E)$ again creates survivors. Thus, the Sisyphus syndrome can go into its next turn. 
For the Sisyphus syndrome to exist, two (possibly lagged) relationships must be operative.

1. Health care expenditure $(H C E)$ must have the effect of increasing remaining life expectancy $(R L E)$. For policy, this effect is of particular importance if it occurs at retirement age because in systems financed by a payroll tax, retired individuals do not contribute to the financing of health care anymore. In tax-based systems, their contribution decreases to the extent that their income drops after retirement.

2. Increasing $R L E$ must translate (through a changed planning horizon and through an increased number of survivors) into an impact on health care spending.

However, the second relationship is confounded in that lower rather than higher $R L E$ is sometimes associated with $H C E$. Evidence is accumulating that much of lifetime $H C E$ is spent during the last year before death (Lubitz and Riley, 1993; Zweifel, Felder and Meier, 1999). In this case, HCE does not generate survivors that will spend more private $H C E$ and exert pressure for more public $H C E$ in the future. At the macroeconomic level, the share of the population that is in their last year of life is reflected by the mortality rate. A high mortality rate (which itself may depend on previous $H C E$ ) is associated with high $H C E$ in the current period while mitigating the dynamics of the Sisyphus syndrome.

As to relationship (1), Zweifel and Ferrari (1992) found that prior HCE in OECD countries did increase $R L E$ at ages 40 and 65. But with regard to relationship (2), they were not able to establish a statistical link between $R L E$ and either public or private $H C E$. The dampening effect of mortality was not accounted for. In all, a Sisyphus syndrome could not be said to exist.

The objective of this contribution is to revisit these findings. In the light of improved specification, data, and econometric methodology, what can be said about the effect of $H C E$ on $R L E$, especially at higher ages? Is it still true that no evidence can be found of a feedback, from increased $R L E$ to $H C E$ ? And is it necessary to control for the mortality rate? Accordingly, the plan of this contribution is as follows. In Section 2, a review of the relevant literature is provided, followed by a more precise restatement of the Sisyphus syndrome. Section 3 is devoted to econometric specification, a description of the data base, and variable definitions. The new empirical evidence is presented in Section 4, while Section 5 contains a summary and conclusion.

\section{Survey of the Literature}

\subsection{The Production of Health}

The seminal article continues to be Auster, Leveson and Sarachek (1969), who related ageand sex-adjusted mortality rates of U.S. states to medical care inputs, schooling, income, and environmental variables. Schooling was negatively related to mortality, medical care inputs not consistently so, while higher income tended to cause an increase in mortality. Hadley (1982) refined this approach, using county groups as unit of analysis. Again, education was negatively related to mortality, income negatively to infant mortality but in mixed ways to adult mortality. A new finding is that most age-sex specific mortality rates depend 
negatively on medical care spending, with an elasticity of -0.15 . Focusing on the elderly, Hadley (1988) found elasticities in the -0.25 to -0.44 range.

An early international study of the production of health is the one by Stewart (1971). Using the nations of the Western hemisphere in the mid-1960s as the unit of analysis, he related life expectancy at birth to medical inputs, literacy rates, and the availability of potable water. All three inputs had small marginal effects in the case of the United States, whereas literacy and potable water showed significant effects in the less developed countries of the group.

Cochrane, St. Leger and Moore (1978) based their analysis on a cross-section of 18 developed countries as of 1970. In their correlation analysis, a greater number of physicians goes along with higher rather than lower mortality (with no attempt to control for reverse causation). Mortality rates correlate negatively with income per capita, suggesting that the positive effect found by Auster, Leveson and Sarachek (1969) might be limited to the United States. They also tested the effects of cigarette and alcohol consumption, with mixed effects. The ambiguous role of income may be due to failure to account for unfavorable life styles that accompany the achievement of higher (labor) income. This is the conclusion that can be drawn from Gerdtham and Ruhm (2004), who find that out of 9 specific causes of mortality in OECD countries, 6 tend to be negatively related to income, while mortality from heart disease displays a strong and significantly positive relationship. At the same time, there is evidence in 5 out of 9 cases that a higher degree of demand pressure in the economy (proxied by a lower unemployment rate) may drive up mortality rates.

Working with a 1980 cross section of OECD countries, Zweifel and Ferrari (1992) introduced lagged $H C E$ (the lag being 10 years due to data availability) as an explanatory variable on the grounds that earlier medical interventions have assured the survival of individuals that make up the current population. Also they replaced mortality by remaining life expectancy (at ages 40 and 65) to better represent the planning situation of forwardlooking individuals. Lagged $H C E$ proved significant, with an elasticity (at the mean) of 0.15 .

More recently Frech III and Miller (1999) review research performed by noneconomists (focused on low-income countries), which tends to support the notion that literacy and diet but not medical care resources are determinants of health. They analyze an OECD cross section, in the main making remaining life expectancy $(R L E)$ at ages 40 and 60 as of 1993 the dependent variable. The explanatory variables include GDP, the consumption of tobacco and alcohol, and the consumption of animal fats. The authors introduce lags of up to ten years (depending on data availability) to capture lifetime effects because variations in most of these variables are unlikely to affect health right away. Rather than considering total $H C E$ only, they single out pharmaceutical consumption to find that this component matters far more than does total $H C E$, which fails to have a significant effect on RLE. In their analysis of a cross section for the year 2000, Miller and Frech III (2004) complement their set of explanatory variables with obesity (which proves significant with the expected sign) but continue to find that pharmaceutical consumption importantly contributes to both $R L E$ at age 40 and 60, both unadjusted and disability adjusted. Their specification is double logarithmic throughout, resulting in the estimation of constant elasticities which necessarily 
imply decreasing marginal productivity of $H C E$ as soon as $H C E$ differs more strongly between countries than does life expectancy (both relative to a benchmark, e.g. the United States).

Although this review may not be complete, the paucity of studies on the production of health is striking. By way of contrast, there has been much more research into the determinants of $H C E$ (to be reviewed in Section 2.2 below). Indeed, one might argue that the separate estimation of a production function is not necessary, based on a duality argument. If individuals acted as perfect cost minimizers in their production of health, the cost function [or an expenditure share function prior to normalization of some price, cf. e.g. Christensen, Jorgenson and Lau (1973)] contains all the information relating to the production technology. However, the estimation of a separate production function of health can be justified by the following arguments:

1. Beyond differentiating between medical and broadly economic explanatory variables, it is still not clear which inputs belong in the health production function and whether their marginal productivities are stable across countries and across time. ${ }^{1}$

2. The health production technology is stochastic rather than deterministic. The deployment of both medical and nonmedical inputs does not always prevent death, i.e. a health outcome that differs strongly from the one intended. This also implies that cost minimization is possible only on expectation, with large deviations that serve to qualify the duality argument.

3. In the case of health, prices contained in the cost or expenditure share function are average prices prior to insurance and public subsidies, while prices governing individual cost minimization are marginal prices often close to zero and different from average prices.

4. Cost minimization is not a very credible hypothesis in health since decisions frequently are made under the influence of physicians. A distortion results to the extent that physicians act as imperfect agents of their patients. Moreover, $H C E$ at the aggregate level may well reflect political institutions.

Conclusion 1. The estimation of a production function for health apart from a cost or expenditure (share) function can be justified. The emerging consensus seems to be that at least some components of health care inputs contribute to health with a lag and decreasing marginal effect.

\subsection{The Health Care Expenditure (HCE) Function}

Kleiman (1974) was one of the first to relate $H C E$ to GDP using a cross-section of OECD country data. He also included the population share of those aged 64+ but was unable to find a statistically significant effect. Accordingly, Newhouse (1977) focused on the relationship between per capita GDP and $H C E$, using a cross-section of OECD countries. The computed income elasticity indicated that health care is a luxury good. This finding was confirmed by Maxwell (1981) in a broad international survey. 
In another regression analysis based on OECD data, Leu (1986) reintroduced the share of persons aged less than 15 years and more than 65 years. However, his main innovation was the argument that a greater share of public in total $H C E$ facilitates budget maximization by bureaucrats, which can be restrained by direct democracy or through central control, as in countries with a National Health Service. These predictions were confirmed but failed to be replicated by later studies.

In their first attempt at identifying the feedback from remaining life expectancy $R L E$ to $H C E$ as part of the Sisyphus syndrome, Zweifel and Ferrari (1992) found RLE at age 65+ to be even negatively related to $H C E$, although without statistical significance. Public $H C E$ turned out to be as much of a luxury good as private $H C E$, with income elasticities far above unity. In a recent analysis of 70 year old Americans, Lubitz et al. (2003) again fail to find a relationship between differences in $R L E$ (indicated by the presence of functional limitations) and projected future $H C E$. However, as will be argued in 2.3 below, it is sufficient for such a relationship to hold in a subset of the population in order to fuel the Sisyphus syndrome.

Collating information from three years to form an OECD panel data set for the first time, Gerdtham et al. (1992) were able to introduce several new explanatory variables, such as physician density, the share of inpatient to total $H C E$, as well as dummies for fee-for-service payment and budgeting caps. In the present context, it is interesting to note that a 10 percent increase in the share of inhabitants aged 64+ (relative to the 15 to 64 age group) was estimated to increase $H C E$ by almost 2 percent, in contradistinction to all studies cited so far.

Extending the period covered to 1970-1991, Gerdtham et al. (1998) introduced a whole host of additional institutional variables. Among them, public reimbursement, capitation of physicians, and patient-first payment with later reimbursement consistently are associated with lower $H C E$. Tobacco consumption proves to be a significant predictor of higher $H C E$. With regard to the share of the elderly population ( $75+$ this time), there is no indication of a significant effect (negative if anything).

A recent concern has been the possibility of spurious regression results due to nonstationarity of time series, in particular $H C E$ and $G D P$. Without directly addressing the nonstationarity issue, Barros (1998) related the growth of $H C E$ from 1960 to 1990 in OECD countries to the growth of GDP. The dummy variables representing gatekeeping systems, public reimbursement, and integrated systems, respectively, all prove insignificant once initial conditions are controlled for. Implied income elasticities range between 0.62 and 0.92 . In their survey, Gerdtham and Jönsson (2000) report very mixed results of studies applying tests designed to detect nonstationarity. Since the emphasis of this contribution is not on the estimation of the income elasticity of $H C E$, this route is not pursued. Rather detrending is sought by transforming the dependent variable into the health share in GDP, resulting in the expenditure share function suggested by duality (normalization by a price should be avoided in this context, see Section 3). In addition, public debate revolves much more about the share of $G D P$ claimed by $H C E$ rather than about $H C E$ per se.

Conclusion 2. With one exception [Gerdtham et al. (1992)], there is no evidence to the effect that a high share of individuals at or in retirement age leads to higher HCE. Other consistently significant regressors are GDP and likely tobacco consumption. 


\subsection{A Combined View: The Sisyphus Syndrome}

The theoretical starting point of this study is the fact that an individual not only has to manage his or her health stock but also a stock of wealth and a stock of human capital ("wisdom", see Figure 1). The dynamic optimization problem amounts to a series of portfolio choices determining the shares held in the guise of wisdom, wealth, and health. Formal modeling has concentrated on the health and wealth components of this portfolio (see Grossman (2000) for a comprehensive review). Certainly with regard to the health component, this lifetime asset management is conditioned by environmental influences (e.g. degree of industrialization, degree of urbanization). The left-hand portion of Figure 1 thus shows the production part of the Sisyphus model.

The right-hand side of Figure 1 contains the derived demand part of the model. HCE is triggered by a gap between desired and actual health stock and influenced by the institutional characteristics of the health care system and relative prices. This implies that $H C E$ is an endogenous determinant of health, a fact that has not been duly recognized in those existing studies on the production of health that introduce contemporaneous $H C E$ as an exogenous explanatory variable. Next, the input of $H C E$ increases (possibly with a lag) actual health stock. If actual health stock remains below a critical level, death occurs, and the Sisyphus cycle comes to an end. If however the stock is sufficient to ensure survival, the individual concerned can count on performing the cycle for a number of periods. The expected number of future rounds defines his or her remaining life expectancy $(R L E)$.

Thus, the feedback from $H C E$ to actual health stock determines the number of survivors who are able to exert demand for health care and hence cause HCE. It is this feedback that is responsible for what can be called the Sisyphus syndrome: Given that $H C E$ is increased exogenously (e.g. by an expansion of public health insurance coverage), more individuals

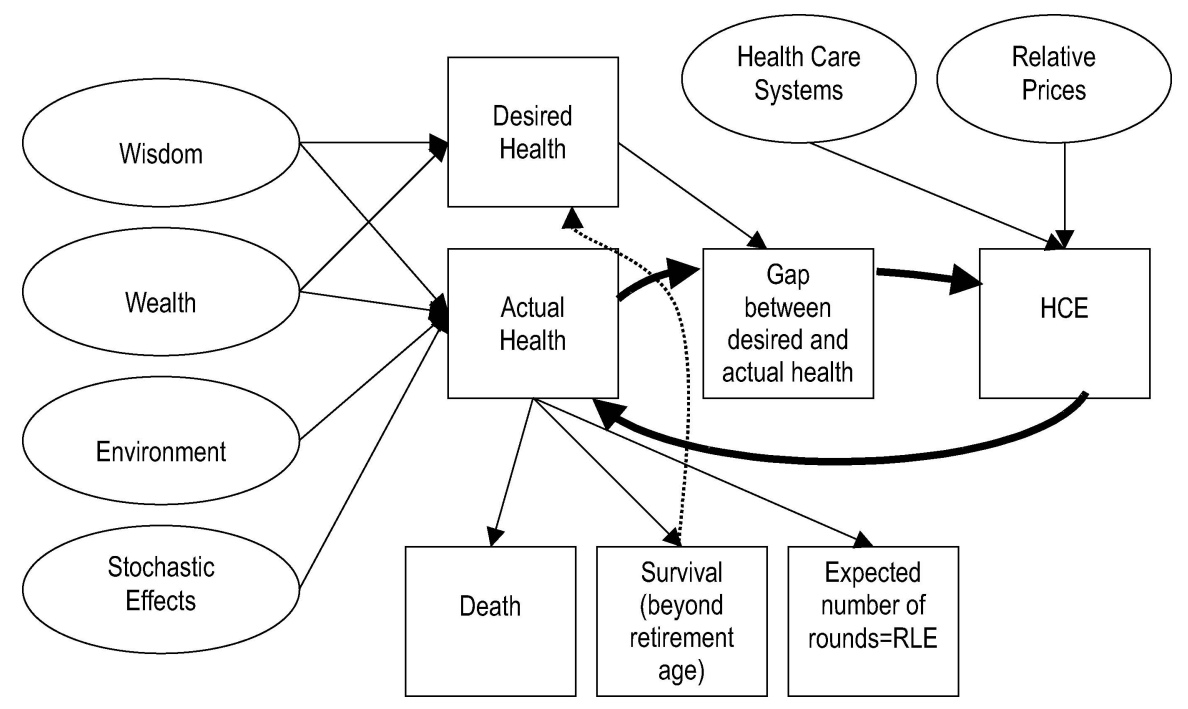

Figure 1. Sisyphus syndrome. 
survive the cycle. Moreover, these individuals have a longer planning horizon thanks to an increased $R L E$. This also means that the optimal health stock should have a higher value, which by itself makes the gap between desired and actual health stock larger, thus calling for additional $H C E$ again (see dashed arrow in Figure 1). On the other hand, the direct effect of $H C E$ is to close the gap between desired and actual health stock. Therefore, the net effect of $H C E$ on the size of this gap remains an open issue, to be examined empirically.

This model motivates the creation of an explanatory variable that has not been introduced in previous work. It will be called SISYPH because it reflects the potential strength of the Sisyphus syndrome. SISYPH is the product of two factors: The first is $R L E$ which shows the number of cycles an individual of a given age expects to perform. However, if the relative number of such individuals in the population is small, $R L E$ by itself will have a small impact on the whole system. Therefore, $R L E$ needs to be weighted by the share of the population at that age as the second factor. Since individuals at retirement age cannot be expected to contribute much to the financing of future $H C E$ (creating a budgetary problem for policy makers), the share of those aged 65 and older will be used in the following.

This description of the Sisyphus syndrome is still not complete, however. Some individuals, having exerted demand for $H C E$ on the expectation to survive for at least one more period, in fact die. Since the gap between desired and actual health stock likely is large in this event, these individuals will have driven up $H C E$ in the current period while not contributing to the Sisyphus syndrome in the future. Therefore, this confounding effect (discussed in Section 1) must be taken into account in order to avoid the risk of overestimating the dynamics of the syndrome. The share of deathbound individuals in a population is given by the mortality rate, MORT. This constitutes another explanatory variable that has been disregarded in published work on $H C E$.

\section{Specification, Data Base, and Variables}

The theoretical considerations laid out in the preceding section provide guidance as to the specification of the relationships constituting the Sisyphus syndrome. Ideally, the hypothesis should be tested using individual panel data; however, data availability dictates the use of aggregate indicators.

In the present situation, two issues need to be clarified. One is choosing the right lags. It turned out that if both GDP and HCE have the same lag, multicollinearity becomes severe. Since the main focus of this paper is on the effect of $H C E, G D P$ is interpreted as a budget constraint rather than a lifestyle variable in the following, suggesting a zero lag, while $H C E$, alcohol consumption, and calorie intake are subjected to different lags. Preliminary estimates showed tobacco consumption to be insignificant, likely because the data base contains too many gaps with respect to this variable. The lags tested for are 3,5, and 10 years, causing the sample to vary both in terms of countries and years covered due to missing values. A Hausman (1978) test is applied to select the preferred lag. It must be admitted of course that any lags exceeding 10 years cannot be discovered in this way.

The other issue is the choice of a random effect vs. fixed effect specification. The advantage of the random effects specification is that it preserves degrees of freedom; on the other hand, the country-specific component of the error term has to be independent of the 
explanatory variables for consistency. Fixed effects provide more information about the peculiarity of a country, but with 30 country-specific dummy variables, multicollinearity quickly becomes a problem. One solution is to drop insignificant dummy variables, which however entails a possible type II error each time. The regression strategy adopted here therefore is to estimate both variants and to decide again on the basis of a Hausman (1978) test.

In view of the uncertainty surrounding the production of health, a specification permitting variable marginal effects is retained for the first part of the Sisyphus model. This consists of equations for remaining life expectancy $(R L E F, R L E M)$ at age 60, the population share of individuals aged 65 and more (POP65, not available according to gender), and the mortality rate of the population as a whole (MORT). Subscripts $i$ (countries) and $t$ (year) are dropped for simplicity except for the error terms and $k=3,5,10$. In the case of random effects, one has,

$$
\left[\begin{array}{l}
R L E F \\
R L E M \\
P O P 65 \\
M O R T
\end{array}\right]=\begin{gathered}
\alpha+\beta_{1} G D P+\beta_{2} G D P 2+\beta_{3} H C E_{-k}+\beta_{4} H C E 2_{-k}+\beta_{5} A L C_{-k} \\
+\beta_{6} A L C 2_{-k}+\beta_{7} C A L_{-k}+\beta_{8} C A L 2_{-k}+v_{i}+\varepsilon_{i t}
\end{gathered}
$$

Since these equations have the same explanatory variables, the $\beta_{1} \ldots \beta_{8}$ denote vectors containing four elements. The same holds true of $v_{i}$ and $\varepsilon_{i t}$ which describe a two-factor random effects specification, with no correlation across the four equations assumed.

In the fixed effects alternative, the United States serves as a benchmark. The maximum of 29 dummy variables, $D_{i}$ is not attained because of multicollinearity. Interestingly, the same 10 countries had to be deleted from the four equations, yet despite this similarity between countries excluded, it proved impossible to benefit from the similarity of those retained. Attempts to group countries with a common dummy variable were not successful. The fixed effects equation thus is defined as follows,

$$
\left[\begin{array}{c}
R L E F \\
R L E M \\
P O P 65 \\
M O R T
\end{array}\right]=\begin{gathered}
\alpha+\beta_{1} G D P+\beta_{2} G D P 2+\beta_{3} H C E_{-k}+\beta_{4} H C E 2_{-k}+\beta_{5} A L C_{-k} \\
+\beta_{6} A L C 2_{-k}+\beta_{7} C A L_{-k}+\beta_{8} C A L 2_{-k}+\gamma^{\prime} D_{i}+\mu_{i t}
\end{gathered}
$$

The variables are defined as follows (see Table 1 for a statistical description) with $k=$ $3,5,10$,

- RLEF: Remaining life expectancy of females at age 60

- RLEM: Remaining life expectancy of males at age 60

- POP65: Population share of individuals aged 65 and more

- MORT: Mortality rate of the population, both genders, all ages, deceased per 100,000 inhabitants

- HCE/GDP: Share of health care expenditure in GDP, both nominal, in percent

- $A L C_{-k}$ : Alcohol consumption per capita, in litres, lagged $k$ years; $A L C 2_{-k}: A L C_{-k}$ squared 
Table 1. Descriptive statistics of variables, 1970-2000.

\begin{tabular}{|c|c|c|c|c|c|}
\hline & $\begin{array}{l}\text { Overall } \\
\text { mean }\end{array}$ & $\begin{array}{l}1970 \\
\min ^{\mathrm{a}}\end{array}$ & $\begin{array}{l}1970 \\
\max ^{\mathrm{a}}\end{array}$ & $\begin{array}{l}2000 \\
\min ^{\mathrm{a}}\end{array}$ & $\begin{array}{l}2000 \\
\max ^{a}\end{array}$ \\
\hline$R L E F$ & 21.973 & 16.0 & 20.9 & 18.2 & 22.9 \\
\hline RLEM & 17.678 & 14.1 & 17.8 & 16 & 21.4 \\
\hline POP65 & 13.369 & 3.1 & 14.1 & $5.3^{\mathrm{b}}$ & $17.8^{\mathrm{b}}$ \\
\hline MORT & 845.888 & 852.3 & 1328.5 & $670.9^{\mathrm{b}}$ & $1173.5^{\mathrm{b}}$ \\
\hline$H C E / G D P$ & 7.571 & 2.584 & 6.951 & $5.412^{\mathrm{b}}$ & $12.865^{\mathrm{b}}$ \\
\hline$R P H$ & 89.820 & 54.8 & 121.6 & 98.6 & 108.1 \\
\hline$G D P$ & 15.762 & 0.272 & 5.027 & 2.974 & 42.315 \\
\hline$H C E_{-10}$ & 0.522 & 0.006 & 0.144 & 0.082 & 2.820 \\
\hline$A L C_{-10}$ & 11.018 & 0.9 & 23.7 & 1.4 & 16.6 \\
\hline$C A L_{-10}$ & 3.048 & 2.096 & 3.467 & 1.870 & 3.705 \\
\hline$\widehat{S Y \widehat{S I P}} H^{\mathrm{c}}$ & 272.165 & & & & \\
\hline$N$ & 233 & & & & \\
\hline
\end{tabular}

${ }^{\text {a }}$ The minima and maxima for 1970 and 2000 were taken over the whole sample available even if the observation was not used in the estimation of Table 5. ${ }^{\mathrm{b}} 1999$.

${ }^{\mathrm{c}}$ Estimated variable, see equation (3) in the text. Values for 1970 and 2000 not available due to missing values of either $P \widehat{O P} 65, \widehat{R L E F}$ or $R \widehat{L E M}$.

- $C A L_{-k}$ : Consumption of kilocalories per capita, lagged $k$ years; $C A L 2_{-k}: C A L_{-k}$ squared

- GDP: GDP per capita, nominal but converted in US $\$ 1,000, G D P 2$ : GDP squared

- $H C E_{-k}$ : Total health care expenditure per capita, nominal but converted in US\$1,000, lagged $k$ years; $H C E 2_{-k} H C E_{-k}$ squared

- $R P H$ : Price index of health care services relative to price index of $G D P$

- SISYPH: Predicted RLE, averaged over gender, multiplied by POP65: [for details, see equation (3)].

The source of all these data is OECD (2001), a source known for several difficulties. One of them is national differences with regard to the delimitation of the health care sector, resulting in different baskets of services, another, the lack of comparability and precision of health care deflators. In view of these difficulties, $H C E$ was not deflated using national price indexes but by the exchange rate when converting the figures into US\$ (avoiding PPP indicators that may contain additional measurement error; see Gerdtham and Jönsson (1991)).

The variable SISYPH is constructed using predicted values from equation (1) or equation (2) as follows,

$$
S \widehat{S Y P} H=(\widehat{R L E F}+R \widehat{L E M}) / 2 * P \widehat{O P} 65
$$


Finally, the derived demand part of the model is specified as an expenditure share, in keeping with the duality considerations of Section 2.1. Thus, the core equation for the health share in the GDP reads as follows with the correct error term added and the dummy variables if needed according to the model in use,

$$
H C E / G D P=\alpha^{\prime}+\beta_{1}^{\prime} G D P+\beta_{2}^{\prime} R P H+\beta_{3}^{\prime} \widehat{M O R} T+\beta_{5}^{\prime} S I \widehat{S Y P} H+\text { error }
$$

Again, no correlation of error terms with those of equations (1) and (2) is admitted. In contradistinction to equations (1) and (2), these equations do not contain squared terms anymore to avoid extreme multicollinearity. The variable $S \widehat{S Y P} H$ already depends on all values of squared regressors (see equations (1) and (2)), while for $R P H$ there is no theoretical reason to enter a squared value when the dependent variable is interpreted as a cost share equation.

\section{Estimation Results}

\subsection{Production of Health}

As stated at the beginning of Section 3, Hausman specification tests were performed to establish both a preferred error structure and choice of lag. Fixed effects (FE) versus Random effects (RE) matched with lags of $(3,5,10)$ years makes for 6 elements that are pitted against each other, or $\frac{6 !}{(6-2) !}=30$ possibilities. This amounts to a total of 15 combinations where one such combination is to take $\mathrm{FE}$ as the maintained hypothesis and to test the RE against it; the other combination in the pair is to take the RE as the maintained hypothesis and to proceed conversely.

It turns out that in all of the 15 two-way comparisons, the FE alternative never dominates without an exception with at least one lag in at least one equation making up (1) or (2). By way of contrast, the RE specification dominates without exception in three of these 15 paired tests, and in an additional three with no more than one exception. On the other hand when the Hausman test is applied to the three lags, $(3,5,10)$ dominate in $(6,2,7)$ comparisons. Both lags 3 and 10 have five exceptions, but in lag 3 , they are multiple in one case. Therefore, the evidence suggests a random effects specification with a lag of $k=10$ years.

4.1.1. The Influence of HCE on Remaining Life Expectancy (RLE) In the original article by Zweifel and Ferrari (1992), remaining life expectancy of males and females at ages 40 and 65 was distinguished, the main motivation being the quadrupling of observations. However, the differences between ages 40 and 60 in the present work proved minimal when the critical values were computed where additional $H C E$ does not affect $R L E$ at the margin. As the policy focus is on individuals approaching retirement, only gender-specific results for age 60 are shown in Table 2.

Contemporaneous GDP (in US\$) is associated with higher RLE in both sexes (with females possibly affected more strongly), confirming results found by Zweifel and Ferrari (1992) as well as Frech III and Miller (1999). A decreasing marginal effect of income cannot 
Table 2. Remaining life expectancy at age 60, 1970-2000.

\begin{tabular}{|c|c|c|c|c|c|c|}
\hline \multirow[b]{2}{*}{$R L E^{\mathrm{a}}$} & \multicolumn{3}{|c|}{ Females } & \multicolumn{3}{|c|}{ Males } \\
\hline & Coefficient & $z$ & $P>z$ & Coefficient & $z$ & $P>z$ \\
\hline$G D P$ & 0.122 & 5.43 & 0.000 & 0.077 & 4.90 & 0.000 \\
\hline$G D P 2$ & -0.002 & -3.91 & 0.000 & -0.001 & -2.95 & 0.003 \\
\hline$H C E_{-10}$ & 2.045 & 4.82 & 0.000 & 2.022 & 4.49 & 0.000 \\
\hline$H C E 2_{-10}$ & -0.565 & -3.60 & 0.000 & -0.491 & -2.95 & 0.003 \\
\hline$A L C L_{-10}$ & -0.043 & -0.70 & 0.484 & 0.022 & 0.23 & 0.822 \\
\hline$A L C 2_{-10}$ & 0.002 & 1.02 & 0.307 & -0.001 & -0.22 & 0.827 \\
\hline$C A L_{-10}$ & 0.786 & 0.65 & 0.515 & -0.723 & -1.08 & 0.281 \\
\hline$C A L 2_{-10}$ & -0.083 & -0.50 & 0.614 & -0.135 & 1.53 & 0.125 \\
\hline constant & 18.572 & 9.11 & 0.000 & 16.883 & 13.94 & 0.000 \\
\hline Wald $\chi^{2}(8)$ : & 210.64 & & & 338.33 & & \\
\hline Prob $>\chi^{2}:$ & 0.0000 & & & 0.0000 & & \\
\hline $1-\frac{\operatorname{var}\left(\varepsilon_{i t}\right)}{\operatorname{var}(R L E F)}$ & 0.601 & & & 0.559 & & \\
\hline$N$ & 303 & & & 303 & & \\
\hline
\end{tabular}

${ }^{a}$ Note: Included in this equation are (frequency): Australia(21), Austria(29), Belgium(22), Canada(12), Denmark(18), Finland(17), Germany(13), Ireland(15), Japan(2), Luxembourg(4), New Zealand(19), Norway(29), Portugal(15), Spain(13), Sweden(16), Switzerland(25), United King$\operatorname{dom}(18)$, U.S.A.(15)

be excluded. The earlier study by Zweifel and Ferrari is also confirmed in that $H C E_{-10}$ results in higher current $R L E$ for both sexes. Since the squared explanatory variable proves highly significant, a critical value can be calculated beyond which additional lagged $H C E$ is counter-productive (flat-of-the curve medicine). Among women, this is approximately US $\$ 1,800$, among men, US $\$ 2,060$, compared to a mean value of US $\$ 1,375$ in 2000 . With regard to the lifestyle indicators, (lagged) consumption of calories and tobacco do not show an influence, whereas alcohol consumption benefits $R L E$ at low levels. Similar findings would have been attained with a lag of 3 rather than 10 years.

4.1.2. Influence of HCE on $65+$ Population Share In order to determine the pressure of individuals faced with a given $R L E$, their population share must be accounted for, resulting in the variable $S I S Y P H$ [defined in equation (3)]. However, the population share of individuals 65 and older might depend on (lagged) $H C E$.

The results of Table 3 do suggest endogeneity of $P O P 65$, but not with regard to $H C E_{-10}$. Specifically, higher GDP goes along with a higher share of aged people (up to some US\$28,750), whereas $H C E$ does not have a discernible effect. The first of these two statements holds also for a lag in $H C E, C A L$ and $A L C$ of 3 years; however, $H C E_{-3}$ would have attained statistical significance. In the life style domain, alcohol consumption clearly serves to increase this share, but with decreasing effect at the margin. The remaining lifestyle variables do not contribute to the determination of POP65, regardless of the choice of lag. 
Table 3. Share of individuals aged 65 and older, 1970-2000.

\begin{tabular}{lcrl}
\hline$P O P 5^{\mathrm{a}}$ & Coefficient & \multicolumn{1}{l}{$z$} & $P>z$ \\
\hline$G D P$ & 0.115 & 6.64 & 0.000 \\
$G D P 2$ & -0.002 & -4.67 & 0.000 \\
$H C E_{-10}$ & 0.626 & 1.35 & 0.177 \\
$H C E 2_{-10}$ & -0.170 & -0.97 & 0.333 \\
$A L C_{-10}$ & 0.174 & 2.75 & 0.006 \\
$A L C 2_{-10}$ & -0.005 & -2.89 & 0.004 \\
$C A L_{-10}$ & -0.274 & -1.40 & 0.161 \\
$C A L 2_{-10}$ & 0.050 & 1.80 & 0.071 \\
constant & 11.270 & 14.15 & 0.000 \\
Wald $\chi^{2}(8):$ & 332.63 & & \\
Prob $>\chi^{2}:$ & 0.0000 & & \\
$1-\frac{\operatorname{var}\left(\varepsilon_{i t}\right)}{\operatorname{var}(P O P 65)}:$ & 0.190 & & \\
$N$ & 394 & & \\
\hline
\end{tabular}

${ }^{a}$ Note: Included in this equation are (frequency): Australia(21), Austria(30), Belgium(30), Canada(30), Denmark(19), Finland(19), France(2), Germany(14), Ireland(30), Japan(2), Luxembourg(12), Netherlands(2), New Zealand(20), Norway(30), Portugal(20), Spain(29), Sweden(17), Switzerland(26), United Kingdom(25), U.S.A.(16)

4.1.3. Influences on Mortality Since mortality is not a core variable of the Sisyphus syndrome but mainly serves to take the surge in $H C E$ towards the end of human life into account, no gender-specific regressions are presented in Table 4. In accordance with early research on the United States [Auster, Leveson and Sarachek (1969)], higher contemporaneous GDP might possibly decrease mortality at the high end of the sample beyond US $\$ 35,000$; the same holds for $H C E_{-10}$, beyond US\$1,490, driving home the argument made above that mortality occurs sooner or later. None of the lifestyle variables are statistically significant. All of these statements prove robust to a lag of 3 rather than 10 years.

\subsection{Explaining the Health Share in the GDP}

In keeping with arguments proffered in Section 2.1, the dependent variable here is $H C E / G D P$. In the earlier estimation of the Sisyphus syndrome by Zweifel and Ferrari (1992), an attempt was made to distinguish between private and public HCE to see whether the feedback from $R L E$ to $H C E$ is particularly marked in the public domain. However, the published literature does not make this distinction because the assignment of total $H C E$ to these two components is far from perfect in many countries, resulting in measurement error (we thank Pedro Pito Barros, Lisbon, for calling our attention to this). With HCE/GDP being the dependent variable, resulting in a filtering out of common trends, measurement errors are expected to play a more important role to begin with. Therefore, the distinction between the private and public components is not made here. All endogenous variables 
Table 4. Influences on mortality, 1970-2000.

\begin{tabular}{lrrr}
\hline MORT $^{\mathrm{a}}$ & Coefficient & \multicolumn{1}{l}{$z$} & $P>z$ \\
\hline$G D P$ & -8.319 & -3.46 & 0.001 \\
GDP2 & 0.118 & 1.84 & 0.065 \\
HCE -10 & -203.305 & -5.68 & 0.000 \\
HCE2 -10 & 68.349 & 4.02 & 0.000 \\
ALC -10 & -16.843 & -1.85 & 0.065 \\
ALC2 -10 & 0.452 & 1.78 & 0.075 \\
CAL -10 & 86.145 & 1.32 & 0.188 \\
CAL2 -10 & -15.036 & -1.78 & 0.075 \\
constant & 1025.007 & 8.42 & 0.000 \\
Wald $\chi^{2}(8):$ & 431.15 & & \\
Prob $>\chi^{2}:$ & 0.0000 & & \\
$1-\frac{\operatorname{var}\left(\varepsilon_{i t}\right)}{\operatorname{var}(\text { MORT) }}:$ & 0.574 & & \\
$N$ & 351 & &
\end{tabular}

${ }^{a}$ Note: Included in this equation are (frequency): Australia(19), Austria(30), Belgium(26), Canada(28), Denmark(16), Finland(16), Germany(13), Ireland(27), Luxembourg(10), New Zealand(19), Norway(28), Portugal(19), Spain(27), Sweden(14), Switzerland(21), United Kingdom(24), U.S.A.(14)

estimated in Section 4.1 enter with their predicted values, using a lag of 10 years (except for $G D P$ ).

Again, the fixed-effects (FE) and the random-effects (RE) specification is based on a Hausman test. This time, FE dominates. This divergence from the health production part of the model is puzzling at first sight. However the production of health depends largely on internationally available medical technology, whereas $H C E$ (as argued at the end of Section 2.1), is also determined by institutional factors that are not so well presented exclusively by an error component whose autocorrelation coefficient is an average over all countries. Indeed, Canada and Germany differ comparatively little (some two percentage points) from the United States (the reference country), Australia, Austria, Portugal and Switzerland form an intermediate group (around three percentage points), while Luxembourg, Spain, and the United Kingdom are estimated to lie four percentage points below the United States, ceteris paribus. Other countries cannot be assigned to one of the groups, either because they fall in between or because they had to be dropped due to multicollinearity (15 cases).

In principle, there could be a problem in particular with the lower bound being zero for $\frac{H C E}{G D P}$. However, calculations using extreme value combinations of explanatory variables inducing low predicted values of $\frac{H C E}{G D P}$ still produced estimates well within the positive range. This result is due mainly due to the small effect of GDP on the health share. In spite of 
the political debate on its rise in major industrial countries, no significant effect of $G D P$ can be discerned. This means that the estimated income elasticity of $H C E$ is 1 (apart from the Sisyphus effect, see below). ${ }^{2}$ This is lower than most elasticities in Gerdtham et al. (1992) but higher than the estimates presented in Gerdtham et al. (1998). As to the role of relative price $R P H$, the theoretical prediction would be that both private and public decision makers tend to substitute health goods for other commodities (aggregated in the GDP) when $R P H$ is high. The positive coefficient of $R P H$ indicates that the implied price elasticity is slightly below one. ${ }^{3}$ Another prediction, already of relevance to the Sisyphus syndrome, is not confirmed, viz. that a higher mortality rate in a given year means a greater number of individuals in their last year of life, causing $H C E$ to be high in that year. The coefficient of $\widehat{M O R} T$ is positive but nonsignificant.

Of course, the variable of crucial interest is $S I \widehat{S Y P} H$, the remaining life expectancy at age 60 weighted by the share of individuals close to retirement age. It has a highly significant coefficient, possibly raising the scepter of an aging population that keeps the spiral in motion indefinitely.

Conclusion 3. The reestimation of the feedback relationship, linking (population shareweighted) remaining life expectancy to the health share in the GDP, yields preliminary statistical evidence of a Sisyphus syndrome.

\subsection{Assessing the Strength of the Sisyphus Syndrome}

The estimates presented in the previous section allow to conclude that there is some preliminary evidence that between 1970 and 2000 a Sisyphus syndrome may have existed. The open question remains of whether the syndrome may be a phenomenon of sufficient importance to merit attention for some or all OECD countries. This calls for the evaluation of the partial derivative $\partial H C E / \partial H C E_{-10}$ : If in a given year during the period of observation, $H C E$ was stepped up, to what extent will later $H C E$ be higher as a consequence of the syndrome (the lag being 10 years as established through specification tests)? If this derivative should exceed unity, this would constitute evidence of a locally explosive cycle; a globally explosive situation can be excluded because all derivatives to be evaluated have critical values where they become zero (linear and quadratic regressors have opposite signs in Tables 2 to 4$)$. The identity

$$
H C E \equiv(H C E / G D P) * G D P
$$

may be used to obtain equation (6), establishing the link between $H C E / G D P$ and $H C E_{-10}$ :

$$
\begin{aligned}
\frac{\partial H C E}{\partial H C E_{-10}} & =\frac{\partial((H C E / G D P) * G D P)}{\partial H C E_{-10}} \\
& =\frac{\partial(H C E / G D P)}{\partial H C E_{-10}} * G D P+(H C E / G D P) * \frac{\partial G D P}{\partial H C E_{-10}} \\
& =\frac{\partial(H C E / G D P)}{\partial H C E_{-10}} * G D P
\end{aligned}
$$


since $\partial G D P / \partial H C E_{-10}$ can be assumed to be zero. Now $H C E_{-10}$ influences current $H C E$ through SISYPH, which is designed to capture the impact of population-weighted $R L E$ on the demand for health care and hence HCE (see equation (3) again). Implicit differentiation then yields,

$$
\begin{aligned}
\frac{\partial(H C E / G D P)}{\partial H C E_{-10}} & =\frac{\partial(H C E / G D P)}{\partial S I S Y P H} * \frac{\partial S I S Y P H}{\partial H C E_{-10}} \\
& =\frac{\partial H C E / G D P}{\partial S I S Y P H} \frac{1}{2}\left[\frac{\partial R L E F}{\partial H C E_{-10}}+\frac{\partial R L E M}{\partial H C E_{-10}}\right] * P O P 65
\end{aligned}
$$

since $\partial P O P 65 / \partial H C E_{-10}$ may be set to zero, according to Table 4. Substituting (7) into (6) and noting that $H C E_{-10}$ is measured in thousands of US\$ and therefore needs to be rescaled,

\begin{tabular}{|c|c|c|c|c|}
\hline$H C E / G D P$ & $n^{\mathrm{a}}$ & Coefficient & $z$ & $P>z$ \\
\hline Dum_Australia & 19 & -3.057 & -7.90 & 0.000 \\
\hline Dum_Austria & 26 & -3.167 & -8.62 & 0.000 \\
\hline Dum_Canada & 12 & -2.179 & -5.35 & 0.000 \\
\hline Dum_Denmark & 16 & -2.466 & -6.26 & 0.000 \\
\hline Dum_Finland & 15 & -3.238 & -8.21 & 0.000 \\
\hline Dum_Germany & 11 & -1.640 & -3.89 & 0.000 \\
\hline Dum_Ireland & 15 & -2.706 & -6.27 & 0.000 \\
\hline Dum_Luxembourg & 4 & -4.375 & -8.45 & 0.000 \\
\hline Dum_New Zealand & 16 & -3.679 & -9.29 & 0.000 \\
\hline Dum_Norway & 28 & -3.515 & -9.64 & 0.000 \\
\hline Dum_Portugal & 8 & -2.890 & -6.33 & 0.000 \\
\hline Dum_Spain & 10 & -4.001 & -8.83 & 0.000 \\
\hline Dum_Switzerland & 21 & -3.081 & -8.14 & 0.000 \\
\hline Dum_UnitedKingdom & 17 & -3.906 & -9.89 & 0.000 \\
\hline$G D P$ & & -0.020 & -1.13 & 0.260 \\
\hline$R P H$ & & 0.012 & 2.03 & 0.042 \\
\hline$\widehat{M O R T}$ & & 0.010 & 1.72 & 0.085 \\
\hline$S I \widehat{S Y P} H$ & & 0.069 & 2.98 & 0.003 \\
\hline constant & & -18.092 & -1.59 & 0.112 \\
\hline Wald $\chi^{2}(18)$ : & & 524.26 & & \\
\hline Prob $>\chi^{2}:$ & & 0.0000 & & \\
\hline $1-\frac{\operatorname{var}\left(\varepsilon_{i t}\right)}{\operatorname{var}(H C E / G D P)}$ & & 0.847 & & \\
\hline$N$ & & 232 & & \\
\hline
\end{tabular}

Table 5. Health share in the GDP, 1970-2000.

${ }^{a}$ Note: that $n$ is the number of country-specific observations, with the benchmark U.S.A. being in the sample 14 times. 
one obtains,

$$
\begin{aligned}
\frac{\partial H C E}{\partial H C E_{-10}}= & \underbrace{\frac{1}{2}} * \underbrace{\frac{\partial(H C E / G D P)}{\partial S I S Y P H}} * \underbrace{\left[\frac{\partial R L E F}{\partial H C E_{-10}}+\frac{\partial R L E M}{\partial H C E_{-10}}\right]} \\
& * \underbrace{P O P 65} * \underbrace{G D P} * \underbrace{\frac{1}{\partial O P}}_{\frac{1}{1000}} \\
= & 0.5 * 0.069 *[1.46+1.51] * 13.60 * 15.76 * 0.001 \approx 0.021
\end{aligned}
$$

The derivatives come from Tables 2 and 5 but have to be evaluated at specific values because the regressors of Table 2 appear not only in linear but also in quadratic form. Neglecting estimated coefficients that are nonsignificant and inserting overall sample means one concludes that US\$1 of $H C E_{-10}$ induces some US\$0.02 of current $H C E$ due to the dynamics of the Sisyphus syndrome. Assuming exponential decay, one could say that 68 percent of a one-time shock to HCE is carried over to the following year $\left(0.68^{10} \approx 0.02\right)$. This is far enough from unity to suggest that the cycle is not explosive.

Conclusion 4. The Sisyphus syndrome seems to have been of some importance during the observation period, with an estimated 68 percent of one US\$ of additional HCE carrying over to the following year, which points to stability.

\section{Summary and Conclusions}

This contribution started from the notion that the production of health and the determination of health care expenditure ( $H C E$ ) should be analyzed jointly. Short of adopting the duality argument to the effect that estimating either a production function or an expenditure (share) function is sufficient, the two links are seen as constituting a dynamic feedback relationship. Once $H C E$ is stepped up exogenously, it may well (with a lag) increase remaining life expectancy and hence the planning horizon of an individual considering an investment in health. This should increase demand for $H C E$, resulting in a feedback that constitutes the Sisyphus syndrome. The macroeconomic importance of this syndrome crucially depends on the remaining life expectancy of those who are at retirement age, beyond which they contribute little to the financing of $H C E$. These considerations call for the construction of the variable $S I \widehat{S Y P} H$, which is the remaining life expectancy at age 60 weighted by the share of individuals aged $65+$, the age discrepancy caused by data availability.

From 1970 to 2000 and among OECD countries, there is confirming evidence for both links. Prior $H C E$ is positively related both to remaining life expectancy at age 60 and the population share of the aged $65+$ and hence the $S I \widehat{S Y P} H$ variable. In its turn, $S I \widehat{S Y P} H$ proves to be a significant determinant of the health share in GDP. An initial HCE increase of US\$1 is estimated to still result in US\$0.02 a decade later as a result of the Sisyphus syndrome. Assuming exponential decay, 68 percent of a one-time shock thus are estimated to carry over to the following year. Since the income elasticity of $H C E$ is estimated to be one ceteris paribus, much of the observed increase of the health share in the GDP can be traced to the Sisyphus syndrome. 
However, one might argue that a Sisyphus syndrome does not really exist. For one, $G D P$ could have been interpreted as a lifestyle variable rather than indicating a budget constraint. This would have called for the introduction of lags for this variable, which could have pointed to delayed adjustments of $\frac{H C E}{G D P}$ even exceeding the 30 years covered by the present sample. In addition, in view of the high degree of multicollinearity between $H C E$ and GDP regardless of the lag selected (simple correlation coefficients always in excess of 0.8538 ), the estimated effects of lagged $H C E$ on remaining life expectancy likely would have dropped and possibly could have lost significance. In that event, there would be no evidence of $H C E$ contributing to the growth of a population segment that has a particular interest in the increased provision of health care services in a later period. Finally some OECD countries have missing values more often than others, which may introduce a selection bias to the extent that those not reporting have less problems with rising $H C E$ (which are interpreted as a reflection of the Sisyphus syndrome in this paper). The countries more consistently represented in the sample might therefore introduce a bias in favor of finding such a syndrome.

While such arguments cannot be rejected out of hand, there are at least two considerations that speak against these. The first is that the hypothesis of a Sisyphus syndrome as a dynamic relationship puts emphasis on lags. Specifically, in previous research on the production of health, contemporaneous $H C E$ was not found to consistently lower mortality rates or increase longevity. However, when introducing a lag of ten years, both Zweifel and Ferrari (1992) and Frech III and Miller (1999) were able to relate remaining life expectancy to previous $H C E$, and this lag is replicated in the present study. Second, the link between production and factor demand theory suggests use of an expenditure share function $(H C E / G D P)$ which is much less influenced by a time trend than $H C E$ itself. And it is with such a detrended dependent variable that $\operatorname{SISYP} H$, whose construction is entirely motivated by the maintained hypothesis, proves highly significant.

On the whole, the evidence suggests that a Sisyphus syndrome may have been operative in the OECD countries until the end of the past century. Although its dynamics are far from explosive, it mirrors the concern of policy makers that the decision to increase health care expenditure could have some similarity with the proverbial ride on a tiger.

\section{Acknowledgment}

The authors wish to acknowledge very helpful criticisms and suggestions from two anonymous referees.

\section{Notes}

1. We owe this important point to one of the referees.

2. The income elasticity of $H C E$ can be calculated as follows. Using $H C E \equiv(H C E / G D P) * G D P$, one obtains $\frac{\partial H C E}{\partial G D P}=\frac{\partial(H C E / G D P)}{\partial G D P} * G D P+\frac{H C E}{G D P}$. The first derivative equals $\beta_{1}^{\prime}$ from equation (4); therefore, the elasticity is given by $e(H C E, G D P)=\beta_{1}^{\prime} *(G D P)^{2} / H C E+1=1$ since $\beta_{1}^{\prime}$ is not significantly different from zero (see Table 5).

3. Since $H C E / G D P$ is formed using nominal figures, it contains $R P H$. Noting that $R P H=P H / P G D P$ (the ratio of the health to the $G D P$ deflator), and using lower case symbols for real quantities, one has (hce/gdp) $* R P H=$ 
$\ldots \beta_{2}^{\prime} * R P H+\ldots$, or $h c e * R P H=\ldots \beta_{2}^{\prime} * R P H * g d p$. Differentiating with respect to $R P H$, one obtains, hce $*(1+\eta)=\beta_{2}^{\prime} * g d p$, where $\eta$ is the elasticity of the demand for health care (hce) w.r.t. RPH. Solving for $\eta$, one obtains $\eta=\beta_{2}^{\prime} *(H C E / G D P)^{-1}-1$. Evaluated at the sample means, this amounts to -0.99 .

\section{References}

Auster, Richard, Irving Leveson and Deborah Sarachek. (1969). "The Production of Health, an Explanatory Study." The Journal of Human Resources 4(4), 411-436.

Barros, Pedro Pita. (1998). "The Black Box of Health Care Expenditure Growth Determinants." Health Economics 7(6), 533-544.

Christensen, Laurits R., Dale W. Jorgenson and Lawrence J. Lau. (1973). “Transcendental Logarithmic Production Frontiers." Review of Economics and Statistics 55(1), 28-45.

Cochrane, A. L., A. S. St. Leger and F. Moore. (1978). "Health Service Input and Mortality Output in Developed Countries." Journal of Epidemiology and Community Health 32(3), 200-205.

Frech III., H. E. and Richard D. Jr. Miller. (1999). The Productivity of Health Care and Pharmaceuticals: An International Comparison. Washington D.C.: The AEI Press.

Gerdtham, Ulf G. and Bengt Jonsson. (1991). Conversion Factor Instability in International Comparisons of Health Care Expenditure.” Journal of Health Economics 10(2), 227-234.

Gerdtham, Ulf G. and Bengt Jonsson. (2000). "International Comparison of Health Care Expenditure.” In: Anthony J. Culyer and Joseph P. Newhouse (eds.), Handbook of Health Economics. Amsterdam, London, New York, Oxford, Paris Shannon, Tokyo: Elsevier, Vol. 1A, chap. 1, pp. 11-53.

Gerdtham, Ulf G., Bengt Jonsson, Maitland MacFarlan and Howard Oxley. (1998). "The Determinants of Health Expenditure in the OECD Countries: A Pooled Data Analysis." In: Peter Zweifel (ed), Health, the Medical Profession, and Regulation. Developments in Health Economics and Public Policy. Boston and Dordrecht: Kluwer Academic, Vol. 6, pp. 113-34.

Gerdtham, Ulf-G. and Christopher J. Ruhm. (2004). "Deaths Rise in Good Economic Times: Evidence from the OECD.” Working Paper, http://www.uncg.edu/eco/cjruhm/papers/oecdl5.pdf.

Gerdtham, Ulf G., J. Sogaard, Bengt Jonsson and F. Andersson. (1992). "A Pooled Cross-Section Analysis of the Health Care Expenditures of the OECD Countries. In Peter Zweifel and III. Frech, H. E. (eds.), Health Economics Worldwide. Developments in Health Economics and Public Policy Series. Boston and Dordrecht: Kluwer Academic, Norwell, Mass, Vol. 1, pp. 287-310.

Grossman, Michael. (2000). “The Human Capital Model.” In: Anthony J. Culyer and Joseph P. Newhouse (eds.), Handbook of Health Economics. Amsterdam, London, New York, Oxford, Paris Shannon, Tokyo: Elsevier, Vol. 1A, chap. 7, pp. 347-408.

Hadley, Jack. (1982). More Medical Care, Better Health? An Econometric Analysis of Mortality Rates. Washington D.C.: Urban Institute Press.

Hadley, Jack. (1988). "Medicare Spending and Mortality Rates of the Elderly.” Inquiry 25(4), 485-493.

Kleiman, E. (1974). "The Determinants of National Outlay on Health.” In: M. Perlman (ed.), The Economics of Health and Medical Care. Basingstoke: Macmillan, London.

Leu, Robert E. (1986). “The Public-Private Mix and International Health Care Costs.” In: Anthony J. Culyer and Bengt Jonsson (eds.), Public and Private Health Services: Complementarities and Conflicts. Oxford and New York: Blackwell, pp. 41-63.

Lubitz, James, Liming Cai, Ellen Kramarow and Harold Lentzner. (2003). "Health, Life Expectancy, and Health Care Spending among the Elderly." The New England Journal of Medicine 349(11), 1048-1055.

Lubitz, James D. and G. F. Riley. (1993). "Trends in Medicare Payments in the Last Year of Life." New England Journal of Medicine 328: 1092-1096.

Maxwell, Robert J. (1981). Health and Wealth. Lexington: Lexington Books.

Miller, Jr., Richard D. and H. E. Frech III. (2004). Health Care Matters. Pharmaceuticals, Obesity, and the Quality of Life. Washington D.C.: AEI Press.

Newhouse, Joseph P. (1977). "Medical Care Expenditure: A Cross-National Survey.” Journal of Human Resources 12(1), 115-125.

OECD (2001). OECD Health Data. Paris. 
Stewart, Jr., Charles T. (1971). "Allocations of Resources to Health.” The Journal of Human Resources 6(1), 103-122.

Zweifel, Peter, Stefan Felder and Markus Meier. (1999). "Ageing of Population and Health Care Expenditure: A Red Herring?" Health Economics 8(6), 485-496.

Zweifel, Peter and Matteo Ferrari. (1992). "Is There a Sisyphus Syndrome in Health Care?" In: Peter Zweifel and H. E., III. Frech (eds)., Health Economics Worldwide. Developments in Health Economics and Public Policy Series. Boston and Dordrecht: Kluwer Academic, Vol. 1, Norwell, Mass, pp. 311-330. 